\title{
BMJ Open Cohort profile: the Mâncio Lima cohort study of urban malaria in Amazonian Brazil
}

\author{
Igor C Johansen, ${ }^{1}$ Priscila T Rodrigues, ${ }^{1}$ Juliana Tonini, ${ }^{1}$ Joseph Vinetz, ${ }^{2}$ \\ Marcia C Castro (D) , ${ }^{3}$ Marcelo U Ferreira (D) ${ }^{1}$
}

To cite: Johansen IC, Rodrigues PT, Tonini J, et al. Cohort profile: the Mâncio Lima cohort study of urban malaria in Amazonian

Brazil. BMJ Open

2021;11:e048073. doi:10.1136/

bmjopen-2020-048073

- Prepublication history and additional supplemental material for this paper are available online. To view these files, please visit the journal online (http://dx.doi.org/10.1136/ bmjopen-2020-048073)

ICJ and PTR contributed equally.

Received 17 December 2020 Accepted 22 October 202

\section{Check for updates}

(C) Author(s) (or their employer(s)) 2021. Re-use permitted under CC BY-NC. No commercial re-use. See rights and permissions. Published by BMJ.

${ }^{1}$ Parasitology, University of Sao Paulo, Sao Paulo, Brazil ${ }^{2}$ Internal Medicine, Yale University School of Medicine, New Haven, Connecticut, USA ${ }^{3}$ Global Health and Population, Harvard School of Public Health, Boston, Massachusetts, USA

Correspondence to Dr Marcelo U Ferreira; muferrei@usp.br

\section{ABSTRACT}

Purpose This population-based open cohort study aims to investigate biological and sociodemographic drivers of malaria transmission in the main urban hotspot of Amazonian Brazil.

Participants Nearly $20 \%$ of the households in the northwestern town of Mâncio Lima were randomly selected and 2690 participants were enrolled since April 2018. Sociodemographic, housing quality, occupational, behavioural and morbidity information and travel histories were collected during consecutive study visits. Blood samples from participants $>3$ months old were used for malaria diagnosis and human genetic studies; samples from participants with laboratory-confirmed malaria have been cryopreserved for genetic and phenotypic characterisation of parasites. Serology was introduced in 2020 to measure the prevalence and longevity of SARSCoV-2 IgG antibodies.

Findings to date Malaria prevalence rates were low (up to $1.0 \%$ for Plasmodium vivax and $0.6 \%$ for $P$. falciparum) during five consecutive cross-sectional surveys between April-May 2018 and October-November $2020 ; 63 \%$ of infections diagnosed by microscopy were asymptomatic. Malaria risk is heterogeneously distributed, with $20 \%$ study participants contributing $86 \%$ of the overall burden of $P$. vivax infection. Adult males are at greatest risk of infection and human mobility across the urban-rural interface may contribute to sustained malaria transmission. Local $P$. vivax parasites are genetically diverse and fragmented into discrete inbred lineages that remain stable across space and time.

Future plans Two follow-up visits, with similar study protocols, are planned in 2021 . We aim to identify highrisk individuals that fuel onwards malaria transmission and represent a priority target for more intensive and effective control interventions.

Trial registration number NCT03689036.

\section{INTRODUCTION}

Although local malaria transmission has decreased substantially over the past two decades, 120 million people continue to have some risk of infection in Latin America and the Caribbean. ${ }^{1}$ The Amazon Basin accounts for approximately $90 \%$ of the malaria cases in the Americas; $72 \%$ of them are due to Plasmodium vivax. Rural communities such

\section{Strengths and limitations of this study}

This is the first population-based cohort study to address the emerging risk of malaria transmission in urbanised spaces in the Amazon.

- Nearly $20 \%$ of the households in town of Mâncio Lima, the main urban malaria hotspot in Brazil, were randomly drawn from census listings and 2690 participants were enrolled and followed-up since April 2018.

- Sociodemographic, occupational, behavioural, and morbidity information, travel histories, and capillary blood samples were collected during five study visits; venous blood from confirmed malaria infections have been cryopreserved for genetic/genomic and phenotypic parasite characterisation.

- Main potential limitations include: (1) generalisability of the study results since the cohort population comprises residents in a single malaria hotspot in the Amazon; (2) loss to follow-up due to the high mobility of the target population; and (3) risk of recall bias during interviews.

as riverine villages, frontier farming settlements, gold mining enclaves, and Amerindian reserves are disproportionally affected. ${ }^{2}$

Despite the low force of infection found across the Amazon, nearly one order of magnitude lower than that in rural Africa, ${ }^{3}$ a minority of highly exposed individuals develops clinical immunity to malaria following infection and eventually constitutes a substantial infectious reservoir comprising asymptomatic parasite carriers that are overlooked by routine surveillance. ${ }^{3-8}$ Importantly, blood from asymptomatic $P$. vivax carriers can infect local malaria vectors despite low mean parasite density. ${ }^{9}$

The Amazon has experienced an accelerated urban growth, characterised by massive rural-to-urban migration, unplanned housing and inadequate infrastructure, that challenges its conventional representation as a densely forested territory interspersed by small and isolated human settlements. ${ }^{10}$ 
Urban residents now account for $72.5 \%$ of the population of the Amazon Basin of Brazil and almost $20 \%$ of the 24.4million Amazonian live in cities with $>500000$ inhabitants. ${ }^{11}$ Importantly, malaria transmission has been increasingly documented within and near densely populated urban centres of the Amazon, ${ }^{12-14}$ with occasional large outbreaks in cities. ${ }^{15}$ We hypothesise that asymptomatic carriers continuously move malaria parasites across the urban-rural interface and contribute significantly to outbreaks and sustained malaria transmission in urbanised spaces in the region. ${ }^{16}$

The dynamics, determinants and public health consequences of urban malaria remain largely unexplored as cities and towns grow and proliferate in the Amazon. This population-based open cohort study was set up to investigate a wide range of biological and sociodemographic factors that drive malaria endemicity in the main urban transmission hotspot of Amazonian Brazil. The long-term goal is to provide scientific evidence that can be translated into effective public health interventions for malaria control and elimination. The original study has since expanded to include SARS-CoV-2 IgG antibody measurements during the ongoing COVID-19 pandemic in this hard-hit region and investigate possible interactions between dengue and COVID-19. ${ }^{17}$

\section{COHORT DESCRIPTION}

\section{Study site}

The Mâncio Lima cohort study aims to investigate malaria epidemiology, diagnostics, transmission dynamics and clinical pathogenesis in Amazonian Brazil. The study site, the town of Mâncio Lima $\left(07^{\circ} 36^{\prime} 51^{\prime \prime} \mathrm{S}, 72^{\circ} 53^{\prime} 45^{\prime \prime} \mathrm{W}\right)$, is situated in the upper Juruá Valley region of Acre State, westernmost Brazil, close to the border with Peru (online supplemental figure 1). Because urban areas in Brazil are defined according to relatively arbitrary administrative rules that do not necessarily consider population density and other internationally adopted criteria, ${ }^{18}$ we delimitated the town of Mâncio Lima essentially as done by the Brazilian Institute of Geography and Statistics but extended the urban area to two urbanised neighbourhoods (Iracema and Pé da Terra) situated along the main road that crosses the town, following 'urbanicity' criteria developed for use in this setting. ${ }^{19}$ At the time of the study onset, the municipality of Mâncio Lima had an annual parasite incidence (number of new laboratory-confirmed malaria cases per 1000 people per year) estimated at 422.8 , the highest for a municipality in Brazil. ${ }^{20}$ With a typical equatorial humid climate, the area receives most rainfall between November and April, but malaria transmission occurs year round. P. vivax accounts for $84 \%$ of local malaria cases and P. falciparum for $14 \% ;<2 \%$ are coinfections with both species. ${ }^{21} P$. vivax infections are routinely treated with chloroquine (total dose, $25 \mathrm{mg}$ of base $/ \mathrm{kg}$ over 3 days) and primaquine ( $0.5 \mathrm{mg}$ of base $/ \mathrm{kg}$ / day for 7 days) and $P$. falciparum infections are treated with a fixed-dose combination of artemether $(2-4 \mathrm{mg} / \mathrm{kg}$ / day) and lumefantrine (12-24 mg/kg/day) for 3 days. ${ }^{22}$ Both treatment regimens remain highly efficacious in this area. $^{2324}$

\section{Study population}

A baseline population census was conducted in Mâncio Lima between November 2015 and April 2016. We enumerated 9124 permanent residents in the urban area, with ages ranging between $<1$ month and 105 years, distributed into 2329 households. ${ }^{21}$ The cohort study sample comprises all members of randomly chosen urban households in Mâncio Lima. We used simple probability sampling to draw 534 households from the list of those enumerated during the baseline census survey. We allowed for up to $2.9 \%$ non-localised or empty houses and refusals and aimed to enrol at least $20 \%$ of all households in the town. Because the target sample size was not reached during the baseline visit, we used a list of randomly chosen substitute households during the second visit to replace households that declined participation or were not located. Because this cohort study was designed to evaluate a wide range of sociodemographic, clinical and laboratory exposures in the same population, no formal a priori sample size and power calculations were made.

\section{Participant recruitment and follow-up}

Figure 1 presents the study flow chart. During the first study visit, between April and May 2018, we targeted the 534 households drawn from the census listings; 1391 residents from 354 households were located and agreed to participate. To achieve the desired sample size, 147 'substitute' households were randomly selected and approached during the second visit, in October-November 2018. The ongoing cohort is dynamic and new residents joining the household (those who moved in or were born between study visits) are enrolled during the follow-up visits. Study participants leaving the sampled households are retained in the cohort as long as they can be located by the field team and their new residences, which are labelled as new households, are situated in the urban area of Mâncio Lima. As a consequence, the total number of households in the sample has increased since the second visit (figure 1). Some study participants could not be located during a follow-up visit but are later 'rescued' during the next visits, as indicated in figure 1; those who die or leave the town are withdrawn. Participants who died, moved away from the study site, and those who withdrew their consent to participate were considered lost for follow-up. Five house visits were carried out until November 2020 and two follow-up visits are planned for 2021. Subject to funding, follow-up will continue after 2021.

\section{Data and sample collection}

Structured questionnaires have been applied to study participants during study visits to obtain and update the demographic, socioeconomic, occupational, behavioural and morbidity information listed in table 1 , which indicates which key variables are individual (one value for 


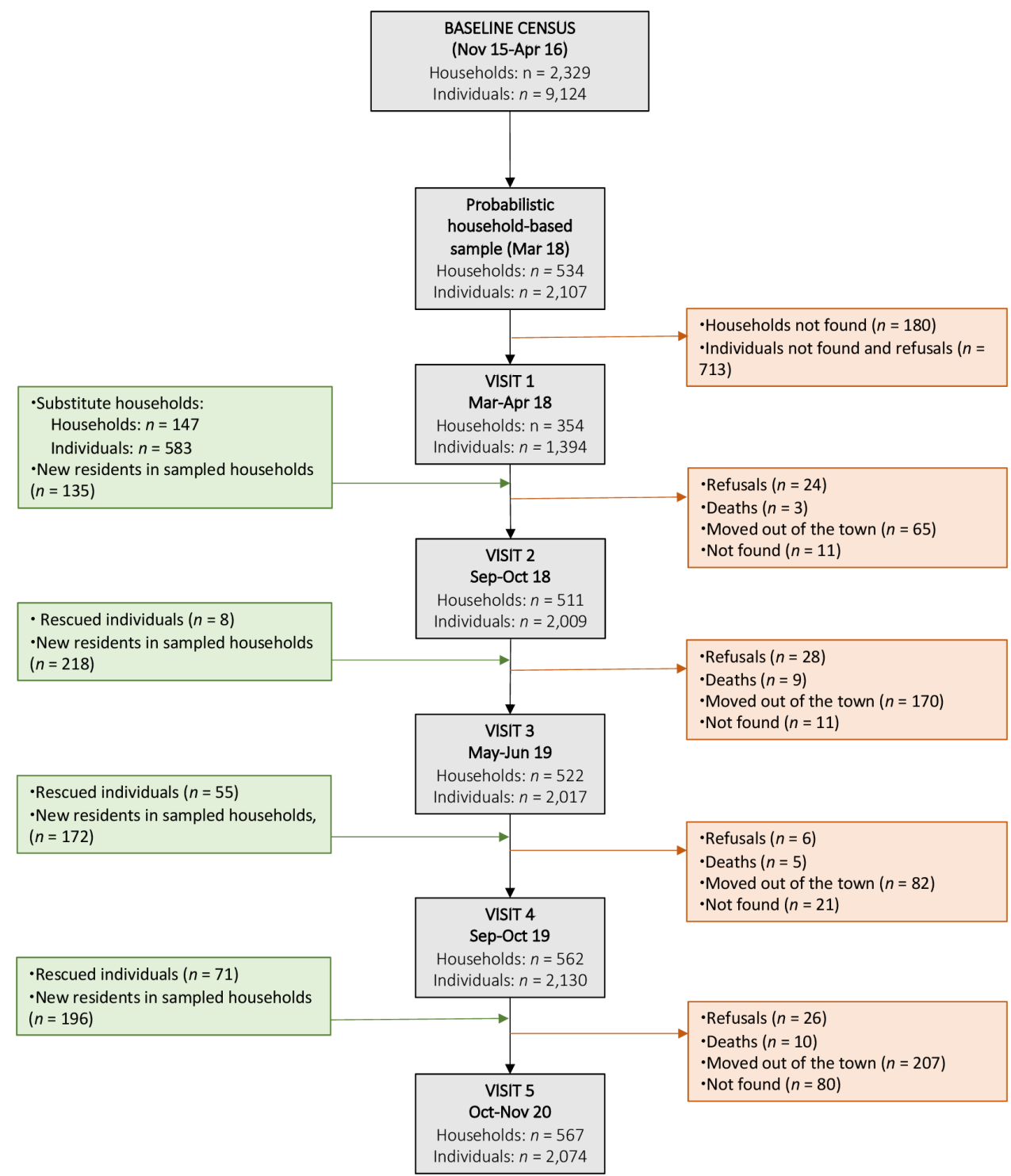

Figure 1 Participant flow chart of the Mâncio Lima cohort study of urban malaria.

each participant) or household-level (the same value attributed to all household members). Dates of follow-up visits and the number of participants interviewed in each visit are shown in table 2 . Both individual and householdlevel information was collected during study visits. For the vast majority of variables, information is missing for $<5 \%$ of participants. GPS coordinates were obtained for all dwellings. Data were entered using tablets programmed with REDCap $^{25}$ and subsequently exported to Stata SE V.15.0 (StataCorp) for statistical analysis. Because study participants are nested into households, which introduces dependency among observations, we have been using mixed-effect logistic or Poisson regression models with random effects at the household level and robust variance for data analysis.

During each visit, household members older than 3 months are invited to provide a finger-prick blood sample for on-site malaria diagnosis by microscopy and antigenbased rapid diagnostic tests. Giemsa-stained thick blood smears have at least 100 fields examined for malaria parasites under $1000 \times$ magnification by experienced local microscopists. Blood aliquots have been stored at $-20^{\circ} \mathrm{C}$ for extraction of human and parasite DNA. Confirmatory molecular diagnosis of malaria has been made with a genus-specific quantitative PCR protocol that targets the mitochondrial genome of human-infecting malaria parasites $^{26}$ followed by species-specific tests. Human genetic studies are underway to identify Duffy blood group polymorphisms that modulate the ability of $P$. vivax merozoites to invade human red blood cells ${ }^{27}$ and analyses of single-nucleotide polymorphisms and copy number variation in the gene encoding the cytochrome P450 (CYP) enzyme CYP2D6 that affect the metabolisation of the antimalarial drug primaquine. ${ }^{28}$ SARS-CoV-2 IgG antibodies were measured by ELISA in samples collected between October and November 2020; to estimate the longevity of SARS-CoV-2 antibody responses, seropositive individuals will be retested within 6 and 12 months.

Study participants with laboratory-confirmed malaria during the study visits are invited to contribute a $5 \mathrm{~mL}$ 
Table 1 Data collected for the Mâncio Lima cohort study of urban malaria

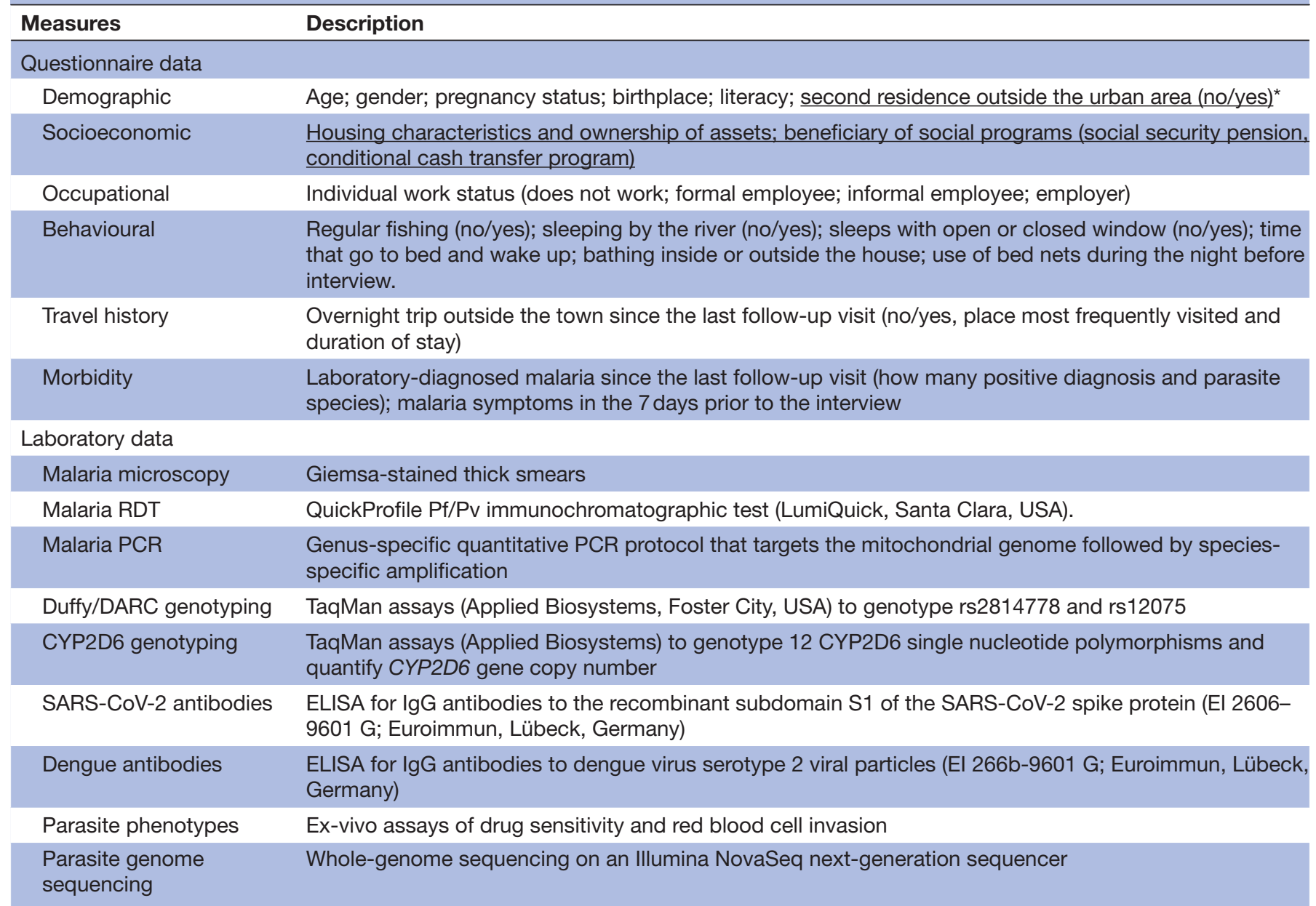

${ }^{*}$ Household-level variables are underlined.

RDT, rapid diagnostic test.

venous blood sample for further genetic/genomic and phenotypic characterisation of infecting parasites. Additional samples have been collected between the visits from consenting malaria patients from Mâncio Lima and surrounding rural sites to map the circulation of parasite lineages over time across the region. BioR01 Plus leukocyte-depletion filters (Fresenius Kabi, Bad Homburg, Germany) are used to reduce human DNA contamination before parasites' genome sequencing. ${ }^{29}$

\section{Additional data sources}

We have routinely retrieved all malaria case notifications in the study population that were entered into the electronic malaria notification system of the Ministry of Health of Brazil (Portuguese acronym, SIVEP-Malaria) since October 2015. Because malaria is a notifiable disease in Brazil and diagnostic testing and treatment are not available outside the network of government-run healthcare facilities, the electronic database comprises the vast majority of laboratory-confirmed malaria episodes countrywide. ${ }^{30}$

Streams, wetlands rich in moriche palm trees, and natural and human-made fish farming ponds are widespread across the town of Mâncio Lima and serve as breeding habitats for malaria vectors. ${ }^{31}$ Potential mosquito breeding sites have been mapped and are continuously monitored for larval density by the local staff of the National Malaria Control Program.

\section{Patient and public involvement}

Study participants had no role in the design, recruitment and conduct of the study. However, they have been regularly informed on project objectives and main results by WhatsApp messages, podcasts and short videos. Links to some of these videos are provided in online supplemental table 1. Local health officers, including National Malaria Control Program personnel, are routinely briefed on study findings during follow-up visits.

\section{FINDINGS TO DATE}

The Mâncio Lima cohort study of urban malaria is ongoing. Online supplemental table 2 shows the sociodemographic characteristics of participants at enrollment. A total of 2690 residents were interviewed during at least one follow-up visit and $981(36.5 \%)$ participated in all 
Table 2 Timeline of measurements for the Mâncio Lima cohort study of urban malaria

\begin{tabular}{|c|c|c|c|c|c|c|}
\hline Variables & $\begin{array}{l}\text { Census survey } \\
\text { (November 15- } \\
\text { April 16) }\end{array}$ & $\begin{array}{l}\text { Visit 1 } \\
\text { (April-May } \\
\text { 18) }\end{array}$ & $\begin{array}{l}\text { Visit } 2 \\
\text { (September- } \\
\text { October 18) }\end{array}$ & $\begin{array}{l}\text { Visit } 3 \\
\text { (April-May } \\
\text { 19) }\end{array}$ & $\begin{array}{l}\text { Visit } 4 \\
\text { (October- } \\
\text { November 19) } \\
\end{array}$ & $\begin{array}{l}\text { Visit } 5 \\
\text { (October- } \\
\text { November 20) }\end{array}$ \\
\hline \multicolumn{7}{|l|}{ Questionnaire data } \\
\hline No participants interviewed & 9124 & 1394 & 2009 & 2017 & 2130 & 2074 \\
\hline Demographic & $\checkmark$ & $\checkmark$ & $\checkmark$ & $\checkmark$ & $\checkmark$ & $\checkmark$ \\
\hline Socioeconomic & $\checkmark$ & $\checkmark$ & $\checkmark$ & $\checkmark$ & $\checkmark$ & $\checkmark$ \\
\hline Occupational & & $\checkmark$ & $\checkmark$ & $\checkmark$ & $d$ & 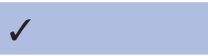 \\
\hline Behavioural & & $\checkmark$ & $\checkmark$ & $\checkmark$ & $\checkmark$ & $\checkmark$ \\
\hline Clinical & & $\checkmark$ & $\checkmark$ & 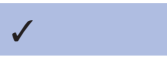 & $s$ & $\checkmark$ \\
\hline Travel history & & & & $\checkmark$ & $\checkmark$ & $\checkmark$ \\
\hline \multicolumn{7}{|l|}{ Laboratory data } \\
\hline No blood samples collected* & & 1082 & 1696 & 1578 & 1768 & 1677 \\
\hline Malaria microscopy & & $\checkmark$ & $\checkmark$ & $\checkmark$ & $\checkmark$ & $\checkmark$ \\
\hline Malaria RDT & & & $\checkmark$ & $\checkmark$ & $\checkmark$ & $\checkmark$ \\
\hline Malaria PCR & & $\checkmark$ & $d$ & $\checkmark$ & $\checkmark$ & $d$ \\
\hline Duffy/DARC genotyping & & $\checkmark$ & $\checkmark$ & $\checkmark$ & $\checkmark$ & $\checkmark$ \\
\hline CYP2D6 genotyping & & $\checkmark$ & $d$ & $\checkmark$ & $\checkmark$ & $d$ \\
\hline SARS-CoV-2 antibodies & & & & & & $\checkmark$ \\
\hline Dengue antibodies & & & & & $d$ & $d$ \\
\hline $\begin{array}{l}\text { Malaria parasite sequencing and } \\
\text { phenotyping } \dagger\end{array}$ & & $\checkmark$ & $\checkmark$ & $\checkmark$ & $\checkmark$ & $\checkmark$ \\
\hline
\end{tabular}

$\checkmark$ denotes that the measurement has been made at the noted study visit.

${ }^{*}$ Finger-prick capillary blood samples collected for malaria diagnosis were used for human genetic and SARS-CoV-2 studies. †Venous blood samples were collected from consenting study participants with laboratory-confirmed malaria and leucocyte depleted for whole-genome sequencing and ex-vivo phenotypic assays.

RDT, rapid diagnostic test.

visits (online supplemental figure 2). Capillary blood was obtained from $77.6 \%$ to $84.4 \%$ of participants in each visit, with a total of 7781 samples collected (table 3). Reasons for not providing blood samples included age below 3 months and inability or refusal to perform a finger puncture. Compared with the total population of Mâncio Lima enumerated during the baseline census, the study sample has a very similar distribution according to sex and age groups (online supplemental figure 3) and place of residence (online supplemental figure 4). Overall malaria prevalence rates determined by microscopy during the study visits ranged between $0.1 \%$ and $1.0 \%$ for $P$. vivax and $0.0 \%$ and $0.6 \%$ for P. falciparum; 39 of 62 (62.9\%) infections were asymptomatic within 1 week prior to blood collection (table 3). Ongoing analyses indicate that our PCR protocol detects up to 10 times more malaria infections than microscopy in cohort participants, but further standardisation and validation are in progress.

Analyses published to date combined baseline information with routinely collected malaria surveillance data. We found a marked heterogeneity in malaria risk in the study population. Adult males are at greatest risk of infection; poor housing and residence in the less urbanised periphery of the town are additional predictors of elevated malaria risk. ${ }^{21}$ Nearly $14 \%$ of the study participants, mostly young children and the elderly, comprise a very low-risk fraction of the population who tend to remain uninfected.$^{21}$ We used compartmental susceptibleinfected-susceptible transmission models to quantify malaria risk heterogeneity at the community level. We estimate that $20 \%$ of the residents contribute $86 \%$ of the overall burden of $P$. vivax infection in Mâncio Lima. ${ }^{3}$ These high-risk individuals eventually develop clinical immunity to malaria and constitute the asymptomatic infectious reservoir that fuels onwards transmission.

To explore the relative contribution of human mobility to malaria in Mâncio Lima, we investigated patterns and determinants of urban-to-rural mobility, which is mostly work-related and places travellers at risk of malaria, and rural-to-urban mobility caused by malaria treatment seeking, which poses an additional risk of infection to urban residents. This information was retrieved from travel histories collected during follow-up visits. We found that the rural localities most frequently visited by urban residents are those with the most intense malaria transmission. These are also the most frequent sources of imported malaria cases diagnosed in the town. The most mobile study participants are unemployed men 
Table 3 Number of malarial infections diagnosed by rapid diagnostic test (RDT) and conventional microscopy, according to the presence of malaria-related symptoms, during five consecutive cross-sectional surveys in the Mâncio Lima, cohort (20182020)

\begin{tabular}{|c|c|c|c|c|c|c|c|c|c|c|c|}
\hline \multirow[b]{3}{*}{ Symptoms } & \multirow[b]{3}{*}{ Species } & \multicolumn{10}{|c|}{ Study visit } \\
\hline & & \multicolumn{2}{|l|}{1} & \multicolumn{2}{|l|}{2} & \multicolumn{2}{|l|}{3} & \multicolumn{2}{|l|}{4} & \multirow{2}{*}{$\begin{array}{l}5 \\
\text { RDT }\end{array}$} & \multirow[b]{2}{*}{ Microscopy } \\
\hline & & RDT & Microscopy & RDT & Microscopy & RDT & Microscopy & RDT & Microscopy & & \\
\hline \multirow{3}{*}{ Yes } & P. vivax & - & 2 & 4 & 8 & 2 & 4 & 0 & 0 & 0 & 2 \\
\hline & Mixed & - & 0 & 0 & 0 & 1 & 0 & 0 & 0 & 0 & 0 \\
\hline & No. tested & - & 218 & 307 & 308 & 182 & 182 & 205 & 205 & 137 & 137 \\
\hline \multirow{3}{*}{ No } & P. vivax & - & 12 & 5 & 5 & 2 & 5 & 3 & 3 & 0 & 1 \\
\hline & Mixed & - & 0 & 0 & 0 & 1 & 1 & 0 & 0 & 0 & 0 \\
\hline & No. tested & - & 864 & 1389 & 1388 & 1396 & 1396 & 1563 & 1563 & 1540 & 1540 \\
\hline \multirow[t]{2}{*}{ Total } & P. falciparum & - & 8 & 8 & 3 & 3 & 6 & 4 & 2 & 0 & 1 \\
\hline & P. vivax & - & 14 & 9 & 13 & 4 & 9 & 3 & 3 & 0 & 3 \\
\hline \multirow{2}{*}{$\begin{array}{l}\text { Prevalence } \\
(\%)\end{array}$} & P. vivax & - & 1.0 & 0.4 & 0.6 & 0.2 & 0.4 & 0.1 & 0.1 & 0.0 & 0.1 \\
\hline & Mixed & - & 0.0 & 0.0 & 0.0 & 0.1 & 0.0 & 0.0 & 0.0 & 0.0 & 0.0 \\
\hline
\end{tabular}

Dates of study visits: 1, April-May 2018; 2, September-October 2018; 3, May-June 2019; 4, September-October 2019; and 5, October-November 2020. Symptoms (at least one present within the past 2 weeks): fever, chills, sweating, headache, nausea, vomiting, myalgia and arthralgia.

16-60years old who maintain both urban and rural residences. $^{32}$

Parasites collected during the study were used to map local and regional transmission pathways of $P$. vivax. We found high genome-level diversity in the $P$. vivax population of Mâncio Lima, but parasites were fragmented into discrete inbred lineages that cocirculate in the host population over extended periods of time. ${ }^{33}$ Microsatellite genotyping of local parasites also revealed the persistence of near-clonal parasite lineages in the town, which have been interpreted as evidence for sustained local $P$. vivax transmission. ${ }^{34}$ We also found significant ancestry sharing between parasites collected at a distance $>700 \mathrm{~km}$, suggesting that $P$. vivax lineages from the Mâncio Lima hotspot seed regional malaria transmission. ${ }^{33}$

We have recently shown that serologically proven prior dengue infection is associated with increased subsequent risk of clinically apparent COVID-19 in this cohort. ${ }^{17}$ Dengue IgG antibodies were detected in $37.0 \%$ of the 1285 cohort participants tested in October-November, 2019, with 10.4 seroconversion events per 100 person years over the following 12 months. In October-November $2020,35.2 \%$ of the participants tested had anti-SARSCoV-2 IgG and $57.1 \%$ of the 448 SARS-CoV-2 seropositives reported clinical manifestations of COVID-19 at the time of infection. Participants aged $>60$ years were twice more likely to have symptomatic COVID-19 than under-five children. Importantly, prior dengue infection was associated with twice the risk of clinically apparent COVID-19 on SARS-CoV-2 infection after adjustment for identified confounders. $^{17}$

\section{Strengths and limitations}

This is the first population-based cohort study of urban malaria in the Amazon. We combine longitudinally collected data and samples to identify demographic, socioeconomic, occupational, behavioural and biological contributors to sustained malaria transmission in urbanised spaces that may represent targets for control interventions. Importantly, the prospective study design enables us to discern temporal associations between exposures and the outcomes of interest and to map the spread of parasite lineages over space and time.

Malaria-related outcomes in the study population have been measured in two ways. First, the point prevalence of infection is determined during each follow-up visit. Conventional and molecular diagnostic tests are carried out on all blood samples, that are collected regardless of any current or recent symptom, allowing us to detect submicroscopic and asymptomatic parasite carriage. Second, the incidence of clinical malaria between study visits is estimated from malaria case notifications in the study population. These are essentially symptomatic infections diagnosed by conventional microscopy. The main limitation of routine surveillance data is that blood samples are not available for further confirmatory diagnostic tests. Moreover, although surveillance comprises virtually all malaria episodes diagnosed by microscopy, 
submicroscopic and asymptomatic malaria episodes experienced by the study population between follow-up visits are overlooked.

There has been considerable cohort attrition from initial recruitment to the most recent follow-up visit, 32 months later. The study population is very mobile and many people are involved in seasonal work in surrounding rural areas. Study participants, especially those who have a second residence, often leave the town either temporally or definitively. This may reduce the statistical power to test for associations between less prevalent exposures and outcomes. New residents in the study households are continuously enrolled and returning participants are recued, keeping the total number of participants remarkably stable between visits 2 and 5 . However, it remains to be determined whether, regarding main study exposures, newly arriving and remaining participants are similarly representative of the target population.

Another study limitation is the risk of recall bias during interviews. For example, information regarding travel, recent mobility and malaria-related symptoms is entirely dependent on participants' reports. It is difficult to know with any precision how many antecedent episodes of malaria infection an individual might have had.

Finally, the cohort includes residents in a single malaria hotspot in the Amazon, which may compromise the generalisability of the main results. However, we argue that malaria transmission is increasingly common in similar urbanised spaces in the Amazon. ${ }^{12-15}$ Extensive deforestation and environmental degradation have displaced vectors to more urbanised areas across the region, where suitable larval habitats, such as natural water bodies and human-made fish farming ponds, are now widespread. ${ }^{13153135-38}$

\section{COLLABORATION}

Datasets from the Mâncio Lima cohort study are not yet openly available, but will be deposited in the ClinEpiDB (https://clinepidb.org/ce/app) repository of population-based epidemiological studies. A repository database has been organised at the University of São Paulo, where future published papers will be made available (https://uspdigital.usp.br/repositorio/). Researchers who are interested in potential collaboration should contact the principal investigator, Marcelo U. Ferreira (muferrei@usp.br), to complete a research plan for evaluation by the Amazonian International Center of Excellence for Malaria Research steering committee.

\section{Twitter Igor C Johansen @igorcavallini}

Acknowledgements The authors thank Ajucilene G. Mota, Francisco Melo and their team at the Health Secretary of Mâncio Lima for overall logistic support, to Rodrigo M. Corder, Anaclara Pincelli, Lais C. Salla, Thaís C. de Oliveira, Vanessa C. Nicolete, Amanda Sampaio, and Madson L. de Oliveira for fieldwork, and Maria José Menezes for her excellent administrative support.

Contributors MUF, JV and MCC planned the cohort. MUF, PTR and ICJ coordinated the fieldwork, with the help of JT, ICJ, MUF and MCC supervised data management and analysis. ICJ and MUF wrote the first manuscript draft with input from all authors, who have read and approved the final version of the manuscript. MUF is the guarantor of this study.

Funding The Mâncio Lima cohort study is part of the National Institutes of Health (NIH)-funded Amazonian International Center of Excellence for Malaria Research network (https://www.niaid.nih.gov/research/amazonian-international-centerexcellence-malaria-research) funded by the National Institutes of Health (NIH), United States (Amazonian International Center of Excellence for Malaria Research, U19 Al089681 to JMV), which also provides a postdoctoral fellowship to ICJ, and by the Fundação de Amparo à Pesquisa do Estado de São Paulo (FAPESP), Brazil (2016/18740-9, 2020/03611-4, and 2020/04505-3 to M.U.F.). PTR receives a scholarship from FAPESP; MUF and RMC receive research scholarships from Conselho Nacional de Desenvolvimento Científico e Tecnológico (CNPq), Brazil (301011/2019-2).

Map disclaimer The inclusion of any map (including the depiction of any boundaries therein), or of any geographic or locational reference, does not imply the expression of any opinion whatsoever on the part of BMJ concerning the legal status of any country, territory, jurisdiction or area or of its authorities. Any such expression remains solely that of the relevant source and is not endorsed by BMJ. Maps are provided without any warranty of any kind, either express or implied.

Competing interests None declared.

Patient consent for publication Not applicable.

Ethics approval The authors assert that all procedures contributing to this work comply with the ethical standards of the relevant national and institutional committees on human experimentation and with the Helsinki Declaration of 1975 , as revised in 2008. Study protocols have been approved by the Institutional Review Board of the Institute of Biomedical Sciences, University of São Paulo, and by the National Committee of Ethics in Research, Ministry of Health of Brazil (CAAE numbers 64767416.6.0000.5467 and 30481820.3.0000.5467). Written informed consent was obtained from all study participants or their parents/guardians.

Provenance and peer review Not commissioned; externally peer reviewed. Data availability statement Data are available upon reasonable request.

Supplemental material This content has been supplied by the author(s). It has not been vetted by BMJ Publishing Group Limited (BMJ) and may not have been peer-reviewed. Any opinions or recommendations discussed are solely those of the author(s) and are not endorsed by BMJ. BMJ disclaims all liability and responsibility arising from any reliance placed on the content. Where the content includes any translated material, BMJ does not warrant the accuracy and reliability of the translations (including but not limited to local regulations, clinical guidelines, terminology, drug names and drug dosages), and is not responsible for any error and/or omissions arising from translation and adaptation or otherwise.

Open access This is an open access article distributed in accordance with the Creative Commons Attribution Non Commercial (CC BY-NC 4.0) license, which permits others to distribute, remix, adapt, build upon this work non-commercially, and license their derivative works on different terms, provided the original work is properly cited, appropriate credit is given, any changes made indicated, and the use is non-commercial. See: http://creativecommons.org/licenses/by-nc/4.0/.

\section{ORCID iDs}

Marcia C Castro http://orcid.org/0000-0003-4606-2795

Marcelo U Ferreira http://orcid.org/0000-0002-5293-9090

\section{REFERENCES}

1 World Health Organization. World malaria report 2020. Geneva: World Health Organization, 2020. https://www.who.int/publications/i/item/ 9789240015791

2 Ferreira MU, Castro MC. Malaria situation in Latin America and the Caribbean: residual and resurgent transmission and challenges for control and elimination. Methods Mol Biol 2019;2013:57-70.

3 Corder RM, Ferreira MU, Gomes MGM. Modelling the epidemiology of residual Plasmodium vivax malaria in a heterogeneous host population: A case study in the Amazon Basin. PLoS Comput Biol 2020;16:e1007377.

4 Alves FP, Durlacher RR, Menezes MJ, et al. High prevalence of asymptomatic Plasmodium vivax and Plasmodium falciparum infections in native Amazonian populations. Am J Trop Med Hyg 2002;66:641-8.

5 Roshanravan B, Kari E, Gilman $\mathrm{RH}$, et al. Endemic malaria in the Peruvian Amazon region of lquitos. Am J Trop Med Hyg 2003;69:45-52. 
6 Ladeia-Andrade S, Ferreira MU, de Carvalho ME, et al. AgeDependent acquisition of protective immunity to malaria in riverine populations of the Amazon Basin of Brazil. Am J Trop Med Hyg 2009;80:452-9.

7 Carrasco-Escobar G, Miranda-Alban J, Fernandez-Miñope C, et al. High prevalence of very-low Plasmodium falciparum and Plasmodium vivax parasitaemia carriers in the Peruvian Amazon: insights into local and occupational mobility-related transmission. Malar J 2017;16:415.

8 Carrasco-Escobar G, Gamboa D, Castro MC, et al. Microepidemiology and spatial heterogeneity of $P$. vivax parasitaemia in riverine communities of the Peruvian Amazon: A multilevel analysis. Sci Rep 2017;7:8082.

9 Alves FP, Gil LHS, Marrelli MT, et al. Asymptomatic carriers of Plasmodium spp. as infection source for malaria vector mosquitoes in the Brazilian Amazon. J Med Entomol 2005;42:777-9.

10 Browder JO. The urban-rural interface: urbanization and tropical forest cover change. Urban Ecosyst 2002;6:21-41.

11 Instituto Brasileiro de Geografia e Estatística (IBGE). Censo Demográfico 2010. Resultados preliminares da amostra [in Portuguese. Rio de Janeiro: IBGE, 2011.

12 Tada MS, Marques RP, Mesquita E, et al. Urban malaria in the Brazilian Western Amazon region I: high prevalence of asymptomatic carriers in an urban riverside district is associated with a high level of clinical malaria. Mem Inst Oswaldo Cruz 2007;102:263-70.

13 Olson SH, Gangnon R, Silveira GA, et al. Deforestation and malaria in Mâncio lima County, Brazil. Emerg Infect Dis 2010;16:1108-15.

14 Almeida ACG, Kuehn A, Castro AJM, et al. High proportions of asymptomatic and submicroscopic Plasmodium vivax infections in a peri-urban area of low transmission in the Brazilian Amazon. Parasit Vectors 2018:11:194.

15 Costa KMdeM, de Almeida WAF, Magalhães IB, et al. [Malaria in Cruzeiro do Sul (Western Brazilian Amazon): analysis of the historical series from 1998 to 2008]. Rev Panam Salud Publica 2010;28:353-60.

16 da Silva-Nunes M, Moreno M, Conn JE, et al. Amazonian malaria: asymptomatic human reservoirs, diagnostic challenges, environmentally driven changes in mosquito vector populations, and the mandate for sustainable control strategies. Acta Trop 2012;121:281-91.

17 Nicolete VC, Rodrigues PT, Johansen IC. Interacting epidemics in Amazonian Brazil: prior dengue infection associated with increased COVID-19 risk in a population-based cohort study. Clin Infect Dis 2021;6:ciab410.

18 Bueno MdoCD, Lima RNdeS. The degree of urbanisation in Brazil. Reg. Stat. 2019;9:72-84.

19 Dal'Asta AP, Lana RM, Amaral S, et al. The urban gradient in malariaendemic municipalities in ACRE: revisiting the role of locality. Int $J$ Environ Res Public Health 2018;15:1254.

20 Ministry of Health of Brazil. List of municipalities belonging to areas at risk or endemic for malaria [in Portuguese. Brasília: Ministry of Health of Brazil, 2019. https://www.saude.gov.br/images/pdf/2019/ junho/25/Lista-de-municipios-pertencentes-as-areas-de-risco-ouendemicas-para-malaria.pdf

21 Corder RM, Paula GA, Pincelli A, et al. Statistical modeling of surveillance data to identify correlates of urban malaria risk: a population-based study in the Amazon Basin. PLoS One 2019:14:e0220980.
22 Ministry of Health of Brazil. Guidelines for malaria therapy in Brazil [in Portuguese. Brasilia: Ministry of Health of Brazil, 2020. https:// portalarquivos2.saude.gov.br/images/pdf/2020/janeiro/29/af-guiatratamento-malaria-28jan20-isbn.pdf

23 Ladeia-Andrade S, Menezes MJ, de Sousa TN, et al. Monitoring the efficacy of chloroquine-primaquine therapy for uncomplicated Plasmodium vivax malaria in the main transmission hot spot of Brazil. Antimicrob Agents Chemother 2019;63:e01965-18.

24 Itoh M, Negreiros do Valle S, Farias S, et al. Efficacy of ArtemetherLumefantrine for Uncomplicated Plasmodium falciparum Malaria in Cruzeiro do Sul, Brazil, 2016. Am J Trop Med Hyg 2018;98:88-94.

25 Harris PA, Taylor R, Thielke R, et al. Research electronic data capture (REDCap)--a metadata-driven methodology and workflow process for providing translational research informatics support. J Biomed Inform 2009;42:377-81.

26 Putaporntip C, Buppan P, Jongwutiwes S. Improved performance with saliva and urine as alternative DNA sources for malaria diagnosis by mitochondrial DNA-based PCR assays. Clin Microbiol Infect 2011;17:1484-91.

27 Zimmerman PA, Ferreira MU, Howes RE, et al. Red blood cell polymorphism and susceptibility to Plasmodium vivax. Adv Parasitol 2013;81:27-76.

28 Marcsisin SR, Reichard G, Pybus BS. Primaquine pharmacology in the context of CYP 2D6 pharmacogenomics: current state of the art. Pharmacol Ther 2016;161:1-10.

29 de Oliveira TC, Rodrigues PT, Menezes MJ, et al. Genome-wide diversity and differentiation in New World populations of the human malaria parasite Plasmodium vivax. PLoS Negl Trop Dis 2017;11:e0005824

30 Daher A, Silva JCAL, Stevens A, et al. Evaluation of Plasmodium vivax malaria recurrence in Brazil. Malar J 2019;18:18.

31 dos Reis IC, Codeço CT, Degener CM, et al. Contribution of fish farming ponds to the production of immature Anopheles spp. in a malaria-endemic Amazonian town. Malar J 2015;14:452.

32 Johansen IC, Rodrigues PT, Ferreira MU. Human mobility and urban malaria risk in the main transmission hotspot of Amazonian Brazil. PLoS One 2020;15:e0242357.

33 de Oliveira TC, Corder RM, Early A, et al. Population genomics reveals the expansion of highly inbred Plasmodium vivax lineages in the main malaria hotspot of Brazil. PLoS Negl Trop Dis 2020;14:e0008808.

34 Salla LC, Rodrigues PT, Corder RM, et al. Molecular evidence of sustained urban malaria transmission in Amazonian Brazil, 20142015. Epidemiol Infect 2020;148:e47.

35 Maheu-Giroux M, Casapía M, Soto-Calle VE, et al. Risk of malaria transmission from fish ponds in the Peruvian Amazon. Acta Trop 2010;115:112-8.

36 Barros FSM, Honório NA. Deforestation and malaria on the Amazon frontier: larval clustering of Anopheles darlingi (Diptera: Culicidae) determines focal distribution of malaria. Am J Trop Med Hyg 2015;93:939-53.

37 Martins LMO, David MR, Maciel-de-Freitas R, et al. Diversity of Anopheles mosquitoes from four landscapes in the highest endemic region of malaria transmission in Brazil. $J$ Vector Ecol 2018;43:235-44.

38 Castro MC, Baeza A, Codeço CT, et al. Development, environmental degradation, and disease spread in the Brazilian Amazon. PLoS Biol 2019;17:e3000526. 